Journal of Telenursing (JOTING)

Volume 3, Nomor 1, Juni 2021

e-ISSN: 2684-8988

p-ISSN: 2684-8996

DOI: https://doi.org/10.31539/joting.v3i1.2115

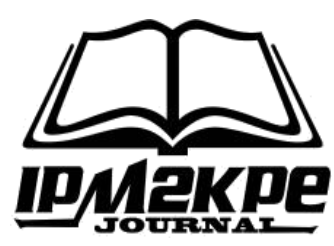

\title{
PENGETAHUAN STIMULASI PERKEMBANGAN ANAK USIA DINI OLEH GURU
}

\author{
Panzilion $^{1}$, Padila ${ }^{2}$, Juli Andri ${ }^{3}$ \\ Universitas Muhammadiyah Bengkulu ${ }^{1,2,3}$ \\ panzilion@umb.ac.id ${ }^{1}$
}

\begin{abstract}
ABSTRAK
Penelitian ini bertujuan untuk melihat gambaran pengetahuan stimulasi perkembangan anak usia dini oleh guru. Metode penelitian yang digunakan dalam penelitian ini adalah metode kuantitatif dengan desain penelitian crossectional dengan menggunakan ChiSquare. Populasi dalam penelitian ini adalah guru di PAUD Aisyiyah X Gading Cempaka sebanyak 20 responden. Teknik pengambilan sampel menggunakan teknik total sampling. Hasil penelitian menunjukkan bahwa gambaran pengetahuan guru PAUD tentang stimulasi perkembangan anak usia dini di PAUD Aisyiah X Kota Bengkulu dari 20 guru, kategori berpengetahuan baik berjumlah 11 responden (50\%), kurang sebanyak delapan responden (20\%) dan cukup sebanyak dua responden (10\%). Simpulan, gambaran pengetahuan guru PAUD tentang stimulasi perkembangan anak usia dini di PAUD Aisyiah X Kota Bengkulu sebagian besar tergolong berpengetahuan baik.
\end{abstract}

Kata Kunci: Guru, Pengetahuan, Stimulasi Perkembangan

\section{ABSTRACT}

This study aims to describe the knowledge of stimulation of early childhood development by the teacher. The research method used in this research is a quantitative method with a cross-sectional research design using the Chi-Square. The population in this study was 20 teachers in PAUD Aisyiyah X Gading Cempaka. The sampling technique used the total sampling technique. The results showed that the description of PAUD teacher knowledge about early childhood development stimulation in PAUD Aisyiah X Bengkulu City from 20 teachers, the excellent knowledge category was 11 respondents (50\%), less than eight respondents (20\%) and enough as many as two respondents (10\%). In conclusion, the description of PAUD teacher's knowledge about stimulating early childhood development in PAUD Aisyiah X Bengkulu City is mostly classified as good knowledge.

Keywords: Teacher, Knowledge, Development Stimulation

\section{PENDAHULUAN}

Anak merupakan generasi penerus suatu bangsa, dimana kualitas tumbuh kembangnya berkisar antara usia 4-6 tahun yang memiliki pertumbuhan dan perkembangan yang sangat pesat dan fundamental pada awal-awal tahun kehidupannya (Maghfuroh \& Chayaning, 2018). Usia dini merupakan masa peka, masa kritis, masa meniru dan masa keemasan perkembangannya, sehingga harus mendapat kesempatan 
luas dalam menemukan pengetahuanya sendiri dengan suasana menyenangkan dan mendapat stimulasi serta dukungan dri pendidik dengan rasa aman dan motivasi yang dapat memacu kreatifitas mereka. Masa tersebut penting dalam tumbuh kembang anak karena masa ini merupakan periode pertumbuhan dasar yang akan mempengaruhi dan menentukan perkembangan anak selanjutnya, sehingga setiap kelainan atau penyimpangan sekecil apapun akan mengurangi kualitas generasi penerus bangsa di kemudian hari (Siswina et al., 2016).

Prasekolah merupakan periode yang sangat penting karena masa ini anak mulai mengenal lingkungan baru, belajar bersosialisasi, mengenal banyak teman sebaya dan proses pembentukan perilaku anak (Ilmiah et al., 2019; Padila et al., 2019; Panzilion et al., 2020). Dihimpun dari beberapa informasi, didapatkan bahwa lebih dari 200 juta anak balita mengalami kegagalan dalam mencapai potensi mereka dalam perkembangannya. Hal tersebut dikarenakan masih kurangnya pemahaman orangtua dalam stimulasi perkembangan anak, terutama di negara berkembang termasuk indonesia (Ramadhani et al., 2018).

Tahun 2018 jumlah anak prasekolah di Indonesia sekitar 21.990 ribu jiwa. Dengan jumlah yang cukup signifikan Indonesia tidak luput dari permasalahan kesehatan salah satunya adalah kesehatan anak yaitu ada sekitar 56,34\% anak prasekolah mengalami keterlambatan pada perkembangan seperti membaca dan menulis. Orang tua dan guru memiliki peranan penting dalam mengawasi perkembangan anak. Orang tua dan guru harus memberikan rangsangan atau stimulasi kepada anak dalam semua aspek perkembangan, baik motorik kasar maupun halus, bahasa dan personal sosial. Stimulasi harus diberikan secara rutin dengan kasih sayang dan metode bermain, sehingga perkembangan anak akan berjalan optimal dan dapat mencegah keterlambatan (Panzilion et al., 2020).

Program deteksi dini dan stimulasi perkembangan merupakan salah satu program pemeriksaan kesehatan yang bertujuan untuk menemukan penyimpangan perkembangan pada balita maupun anak usia prasekolah secara dini, menyeluruh dan terkoordinasi diselenggarakan dalam bentuk kemitraan antara keluarga (orang tua, pengasuh anak dan anggota keluarga lainnya), masyarakat (kader dan organisasi profesi) dengan tenaga profesional. Pemantauan perkembangan anak meliputi pemantauan dari aspek fisik, psikologis dan sosial (Ulfa, 2018; Padila et al., 2019).

Selain bentuk kemitraan antara keluarga, masyarakat dan tenaga profesional, Pendidikan Anak Usia Dini (PAUD) juga merupakan lembaga yang memiliki peran dalam pertumbuhan dan perkembangan anak. Guru PAUD memiliki peran untuk memberikan stimulasi dan memonitor perkembangan anak. Salah satu upaya mencegah terjadinya masalah perkembangan anak, maka perlu dilakukan upaya pemberdayaan guru PAUD agar mampu melakukan deteksi dini perkembangan anak (Kristiawati \& Yunitasari, 2018).

Guru sebagai tokoh sentral dituntut untuk mampu menguasai empat kompetensi dasar seorang guru yakni kompetensi pedagogik, kompetensi profesional, kompetensi kepribadian dan kompetensi sosial. Untuk itu guru dituntut untu dapat mengembangkan kompetensinya melalui belajar dari berbagai program pelatihan baik dari segi sarana dan prasarana serta fasilitas yang telah disediakan di sekolah maupun di luar sekolah. Namun berbagai fenomena yang telah dijumpai dalam dunia pendidikan Indonesia saat ini, masih terdapat guru yang belum memenuhi standarisasi kompetensi professional dan kualifikasi akademik guru. Setelah ditelusuri, ternyata masih terdapat guru yang mengajar tidak sesuai dengan latar belakang pendidikan guru tersebut. Akibatnya 
mereka membawakan materi pelajaran yang tidak sesuai dengan latar belakang pendidikannya terkadang mengajar hanya sekedar untuk tuntutan profesi, tanpa disertai niat dan kemauan untuk meningkatkan kualitas peserta didik. Hal ini disebabkan karena jumlah guru di Indonesia masih dianggap kurang jika dikaitkan dengan jumlah anak didik yang ada, distribusi guru bidang keilmuan yang kurang merata (Qomario et al., 2018).

Profil pendidik guru mewakili gambaran tujuan pendidikan nasional yang akan dicapai, yakni menyiapkan anak yang berkembang menjadi dewasa secara utuh, beriman, bertaqwa dan berakhlak mulia. Untuk mencerdaskan anak didiknya, guru haruslah mencerdaskan dirinya dahulu, baik cerdas di bidang spiritual yang dapat membimbing anak didiknya menjadi manusia yang beriman dan berakhlak mulia, cerdas menguasai, menerapkan dan mengembangkan keilmuannya serta cerdas dalam merawat kesehatan jasmani-rohani dan sosialnya, sehingga patut ditiru (Qomario et al., 2018).

Berdasarkan hasil temuan Winarsih \& Hartini (2020) cakupan pelayanan kesehatan anak yang terdiri dari pemantauan perkembangan dan stimulasi dini tumbuh kembang untuk peningkatan pengetahuan guru PAUD tentang deteksi tumbuh kembang usia prasekolah dengan menggunakan metode kegiatan pengabdian masyarakat mencapai angka peningkatan pengetahuan sebesar 75,82\%. Menurut Intarti (2019) sebagian besar pengetahuan guru PAUD sebelum diberi intervensi Komunikasi Informasi dan Edukasi (KIE) tergolong kategori cukup sebanyak 22 responden (88\%) dan baik sebanyak 3 responden (12\%). Adapun setelah diberi KIE, sebagian besar pengetahuan guru PAUD masuk kategori cukup dengan jumlah responden sebanyak 2 orang (8\%) dan baik sebanyak 23 responden (92\%). Dengan demikian dapat disimpulkan bahwa terdapat pengaruh KIE terhadap tingkat pengetahuan guru PAUD tentang stimulasi perkembangan kecerdasan otak anak usia dini.

Beberapa hasil riset terdahulu, telah menelaah tentang pengetahuan guru dalam pemantauan pertumbuhan dan stimulasi perkembangan otak anak, namun sejauh ini belum ada yang mengkaji empat sektor perkembangan anak sekaligus, mulai dari stimulasi motorik kasar dan halus, bahasa dan sosial. Oleh karena itu, peneliti tertarik untuk mengkaji empat sektor tersebut pada penelitian ini guna optimalisasi perkembangan anak usia dini.

\section{METODE PENELITIAN}

Penelitian ini berjenis kuantitatif dengan desain penelitian crossectional menggunakan rumus Chi-Square. Populasi target dalam penelitian ini adalah guru di PAUD Aisyiyah X Gading Cempaka sebanyak 20 responden. Pengambilan sampel dilakukan menggunakan teknik total sampling. Alat ukur yang digunakan adalah kuesioner dengan modifikasi pengetahuan terkait stimulasi perkembangan anak usia dini. 


\section{HASIL PENELITIAN}

\section{Karakteristik Responden}

Karakteristik responden dijabarkan berdasarkan usia, pendidikan dan masa kerja dapat dijelaskan sebagai berikut:

Tabel. 1

Karakteristik Responden Berdasarkan Usia Guru di PAUD Aisyiah X Kota Bengkulu

\begin{tabular}{cccc}
\hline No & Usia Guru & Frekuensi (f) & Persentase $(\%)$ \\
\hline 1. & 18 tahun & 3 & 15 \\
2. & 20 tahun & 3 & 15 \\
3. & 22 tahun & 4 & 20 \\
4. & 24 tahun & 8 & 40 \\
5. & $>26$ tahun & 2 & 10 \\
\hline & Total & 20 & 100 \\
\hline
\end{tabular}

Hasil pada tabel 1 menunjukkan bahwa dari 20 responden sebagian besar usia guru PAUD dalam penelitian ini berusia 24 tahun yang berjumlah 8 responden (40\%), usia 18 tahun sebanyak 3 responden (15\%), usia 20 tahun berjumlah 3 responden (15\%), usia 22 tahun berjumlah 4 responden $(20 \%)$ dan usia $>26$ tahun berjumlah 2 responden $(10 \%)$.

Tabel. 2

Karakteristik Responden Berdasarkan Pendidikan Guru di PAUD Aisyiah X Kota Bengkulu

\begin{tabular}{cccc}
\hline No & Pendidikan Guru & Frekuensi (f) & Persentase (\%) \\
\hline 1. & SMA & 14 & 70 \\
2. & D3 & 5 & 25 \\
3. & S1 PAUD & 1 & 5 \\
\hline & Total & 20 & 100 \\
\hline
\end{tabular}

Data pada tabel 2 menunjukkan bahwa dari 20 responden sebagian besar guru PAUD memiliki pendidikan SMA berjumlah 14 responden (70\%), serta pendidikan D3 berjumlah 5 responden (25\%) dan pendidikan S1 PAUD hanya 1 responden (5\%).

Tabel. 3

Karakteristik Responden Berdasarkan Masa Kerja Guru di PAUD Aisyiah X Kota Bengkulu

\begin{tabular}{cccc}
\hline No & Masa Kerja & Frekuensi (f) & Persentase $(\%)$ \\
\hline 1. & 5 bulan & 3 & 15 \\
2. & 1 tahun & 10 & 50 \\
3. & 1,5 tahun & 4 & 20 \\
4. & $>1,5$ tahun & 3 & 15 \\
\hline & Total & 20 & 100 \\
\hline
\end{tabular}

Berdasarkan hasil pada tabel 3, diketahui bahwa dari 20 responden sebagian besar masa kerja guru PAUD selama 1 tahun berjumlah 10 responden $(50 \%)$, kemudian masa kerja selama 1,5 tahun berjumlah 4 responden (20\%), masa kerja 5 bulan berjumlah 3 responden (15\%), dan masa kerja $>1,5$ tahun berjumlah 3 responden $(15 \%)$. 


\section{Gambaran Pengetahuan}

Gambaran pengetahuan stimulasi perkembangan anak usia dini yang dimiliki guru di PAUD Aisyiah X dapat dijabarkan sebagai berikut:

Tabel. 4

Gambaran Pengetahuan Stimulasi Perkembangan Anak Usia Dini oleh Guru di PAUD Aisyiah X Kota Bengkulu

\begin{tabular}{cccc}
\hline No & Pengetahuan Stimulasi Guru & Frekuensi (f) & Persentase $(\%)$ \\
\hline 1. & Baik & 10 & 50 \\
2. & Cukup & 2 & 10 \\
3. & Kurang & 8 & 40 \\
\hline & Total & 20 & 100 \\
\hline
\end{tabular}

Berdasarkan tabel 4, data menunjukkan bahwa sebagian besar pengetahuan stimulasi perkembagan anak usia dini oleh guru dalam penelitian ini adalah baik sebanyak 10 responden (50\%), kemudian kurang sebanyak 8 responden $(20 \%)$ dan cukup sebanyak 2 responden (10\%).

\section{PEMBAHASAN}

\section{Karakteristik Responden}

Berdasarkan tabel 4, gambaran tingkat pengetahuan yang mempengaruhi pengetahuan guru PAUD tentang stimulasi perkembangan anak prasekolah usia 3-5 tahun di PAUD Aisyiah X Kota Bengkulu menunjukkan bahwa dari 20 responden, sebanyak 11 responden (50\%) baik dalam mengetahui tentang stimulasi perkembangan anak, sebanyak 2 responden (10\%) cukup mengetahui tentang stimulasi perkembangan anak dan sebanyak 8 responden $(40 \%)$ kurang dalam mengetahui tentang stimulasi perkembangan anak.

Pengetahuan merupakan hasil tahu dan ini terjadi setelah orang melakukan pengindraan terhadap suatu objek tertentu. Pengindraan terjadi melalui panca indra manusia yakni indra penglihatan, pendengaran, penciuman rasa dan raba. Adapun faktor-faktor yang mempengaruhi pengetahuan adalah jenis kelamin, umur, pendidikan dan masa kerja (Primihastuti, 2020). Perkembangan sosial pada anak usia prasekolah termasuk ke dalam golden period dimana masa tersebut tidak bisa diulang lagi. Faktor yang mempengaruhi perkembangan sosial pada anak adalah deteksi dini dan strategi stimulasi perkembangan sosial pada anak prasekolah (Nurhidayah et al., 2020).

Hasil penelitian pada guru PAUD Aisyiah X Kota Bengkulu mengenai karakteristik usia guru menunjukkan bahwa sebagian besar usia guru PAUD dalam penelitian ini 24 tahun yang berjumlah 8 responden (40\%). Pengetahuan dipengaruhi oleh umur, semakin cukup umur, tingkat kematangan dan kekuatan seseorang akan lebih matang dalam berfikir dan bekerja (Rahayu \& Purnamasari, 2019). Guru memiliki kewajiban untuk meningkatkan kualitas pembelajaran sesuai dengan perkembangan ilmu pengetahuan, teknologi dan seni agar tugas perkembangan anak dapat dicapai (Qomario et al., 2018). Dalam mengembangkan kualitas pembelajaran dapat dilihat dari pengalaman yang telah guru peroleh dan produktivitas guru yang dilihat dari kategori usia.

Berdasarkan hasil penelitian karakteristik pendidikan pada tabel 2, data memperlihatkan bahwa dari 20 responden sebagian besar guru PAUD memiliki pendidikan SMA berjumlah 14 responden (70\%). Pengetahuan diperoleh dari pendidikan. Semakin tinggi pendidikan, maka pengetahuan yang diberikan akan lebih 
baik dibandingkan mereka yang berpengetahuan rendah, sehingga yang berpengetahuan lebih baik akan semakin paham dengan materi strategi dan mampu menerapkannya (Riyadi \& Sundari, 2020).

Latar belakang pendidikan guru dapat mempengaruhi pola pikir guru baik formal maupun non formal dalam mendidik anak. Hal ini sejalan dengan hasil temuan Imelda (2017) bahwa pengetahuan yang kurang baik dilatarbelakangi oleh pendidikan terakhir yang rendah. Demikian juga menurut Intarti (2019) bahwa pengetahuan dipengaruhi oleh pendidikan, semakin tinggi tingkat pendidikan seseorang maka semakin mudah ia mendapatkan informasi sehingga banyak pula pengetahuan yang dimilikinya. Sebaliknya jika tingkat pendidikannya rendah, maka individu tersebut akan mengalami kesulitan dalam menerima informasi terlebih mengaplikasikannya dalam kehidupan sehari-hari.

Menurut Setyaningsih \& Anggasari (2017) faktor-faktor yang mempengaruhi tingkat pengetahuan salah satunya adalah pendidikan. Pendidikan diperlukan untuk mendapat informasi misalnya hal-hal yang menunjang kesehatan, sehingga dapat meningkatkan kualitas hidup. Dengan pendidikan tingkat menegah dimungkinkan responden memperoleh informasi lebih banyak daripada responden dengan pendidikan yang lebih rendah.

Data karakteristik masa kerja pada tabel 3 menunjukkan bahwa dari 20 responden sebagian besar guru bekerja selama 1 tahun berjumlah 10 responden (50\%). Masa kerja adalah lama waktu untuk melakukan suatu kegiatan tau lama waktu seseorang sudah bekerja. Masa kerja merupakan rentang waktu yang telah ditempuh oleh seseorang dalam melaksanakan tugasnya, selama waktu itulah banyak pengalaman dan pelajaran yang dijumpai, sehingga sudah mengerti yang menjadi tugas dan tanggung jawabanya. Lamanya masa kerja menggambarkan pengalaman seseorang dalam menguasai bidang tugasnya.

Guru PAUD dengan pengalaman kerja yang banyak lebih memahami cara menstimulasi anak usia dini dibandingkan dengan guru PAUD yang pengalaman kerjanya sedikit. Semakin lama masa kerja pada suatu organisasi, maka akan semakin berpengalaman orang tersebut, sehingga kecakapan kerjannya dan tingkat pengetahuannya semakin baik (Intarti, 2019). Berdasarkan hasil penelitian yang dilakukan oleh Suryandari \& Purwanti (2018) semakin lama seseorang bekerja maka akan semakin berpengalaman di bidang pekerjaanya, sehingga semakin lama menjadi guru PAUD, maka pengalaman untuk menguasai proses mengajar anak semakin banyak.

Kinerja guru tidak terlepas dari peserta didik sebagai subjek didik dan tingkat prestasi belajar serta guru sebagai perencana dan pengelola pembelajaran. Guru dinilai bedasarkan kemampuan mereka untuk menerapkan tujuan pendidikan. Anggota staf pendukung dinilai berdasarkan kemampuan mereka untuk menerapkan tujuan pendidikan. Dalam sebagian besar pengaturan pendidikan, semua anggota staf dievaluasi minimal setahun sekali. Guru akan sering menerima dan mendapat manfaat dari ulasan yang lebih sering (Ilvagustina, 2016).

Kemampuan guru untuk merencanakan pembelajaran terkait erat dengan pemahaman guru terhadap kurikulum yang digunakan. Merencanakan pembelajaran dan melakukan evaluasi hasil belajar merupakan indikator penting akan terlihat dalam kinerja guru (Herlinda, 2017). Pemberian materi pembelajaran anak usia dini didasarkan pada suatu yang nyata dan pendidikan yang layak bagi anak usia prasekolah. 
Metode pengemabangan yang digunakan penuh dengan inspirasi, sehingga mampu memperkenalkan anak terhadap suatu dimensi baru dengan menyenangkan dalam pendidikan. Pendidikan pada masa usia dini harus mengembangkan kemampuan agar anak bertindak secara kreatif (Dewi \& Suryana, 2020).

\section{Gambaran Pengetahuan Stimulasi Responden}

Hasil penelitian pada tabel 4 tentang gambaran pengetahuan menunjukkan bahwa sebagian besar pengetahuan stimulasi perkembangan anak usia dini oleh guru dalam penelitian ini adalah baik sebanyak 10 responden $(50 \%)$. Berdasarkan hasil literatur Saputri (2019) menunjukkan bahwa untuk meningkatkan perkembangan sosial anak yaitu dengan pemberian stimulasi karena dengan pemberian stimulasi yang optimal mampu meningkatkan perkembangan anak secara baik. Dalam penelitianya didapatkan hampir seluruh anak dengan perkembangan yang sesuai $(96,9 \%)$ dan mendapatkan stimulasi yang baik.

Temuan di atas sejalan dengan penelitian Riyadi \& Sundari (2020) bahwa pengetahuan yang baik akan memberikan hasil yang baik dan begitu pula sebaliknya, apabila pengetahuan yang kurang baik juga akan meghasilkan yang kurang baik. Namun pengetahuan seseorang juga tidak luput dari faktor yang mempengaruhi mulai dari faktor internal maupun eksternal seseorang itu sendiri.

Menurut Nurhidayah et al., (2020) pemberian stimulasi perkembangan sosial bisa dilakukan oleh orang tua, guru ataupun keluarga si anak. Salah satu contoh pemberian stimulasi perkembangan yaitu melalui media bermain, senam dan seni visual art. Stimulasi perkembangan sosial yang paling efektif dalam meningkatkan perkembangan anak adalah stimulasi bermain. Kegiatan bermain telah terbukti mampu meningkatkan perkembangan sosial, emosional serta fisik anak (Ramadhani et al., 2018).

Hasil penelitian yang dilakukan oleh Kristiawati \& Yunitasari (2018) memperlihatkan adanya peningkatan pertumbuhan dan perkembangan anak usia dini melalui program pemberdayaan PAUD. Menurutnya tingkat pengetahuan tentang pertumbuhan dan perkembangan anak meningkat untuk kategori baik dari hasil pre test 68,75\% menjadi 93,75\%, pengetahuan deteksi perkembangan untuk kategori baik dari hasil data pre test $12,5 \%$ meningkat sebesar $68,75 \%$ dan pengetahuan alat permainan edukatif pada kategori baik dari hasil data pre test $0 \%$ meningkat sebesar $62,5 \%$.

Berdasarkan hasil penelitian yang telah didapatkan, potensi berkelanjutan program guru PAUD yang telah terlatih dapat membagikan pengetahuan dan keterampilan yang dimiliki kepada orang tua murid. Diharapkan guru PAUD tidak hanya memiliki kemampuan dalam pengajaran, namun juga lebih memperhatikan aspek perkembangan anak didik mereka. Hasil kegiatan Yuliani (2018) dalam pelatihan stimulasi deteksi intervensi dini tumbuh kembang (SDIDTK) bagi guru dan wali murid PAUD menunjukkan adanya peningkatan pengetahuan antara sebelum dan setelah pelaksanaan, terlihat dari hasil rerata skor pre test yaitu sebesar 62,5 dan post test 81,39. Didukung oleh penelitian Novianti et al., (2018) bahwa ada peningkatan pengetahuan guru setelah diberikan intervensi perkembangan dengan rata-rata kenaikan mencapai 13,06\%.

\section{SIMPULAN}

Gambaran pengetahuan guru PAUD tentang stimulasi perkembangan anak usia dini di PAUD Aisyiah X Kota Bengkulu sebagian besar tergolong berpengetahuan baik. 


\section{SARAN}

\section{Bagi Kepala PAUD}

Memberikan kesempatan kepada guru untuk dapat mengikuti kegiatan seminar, pelatihan dan workshop yang berkenaan dengan pengetahuan stimulasi perkembangan anak usia dini serta memonitor rencana kegiatan pembelajaran yang telah dibuat guru, guna melihat kreativitas keragaman dalam menstimulasi perkembangan anak usia dini.

\section{Bagi Guru PAUD}

Memperbanyak referensi terkait pengetahuan stimulasi perkembangan anak usia dini dan mengikuti kegiatan seminar, pelatihan dan workshop yang berkaitan dengan kemampuan menstimulasi perkembangan anak usia dini.

\section{Peneliti}

Bagi peneliti selanjutnya dapat dijadikan sebagai bahan referensi untuk melakukan penelitian sejenis dan lebih lanjut dalam bidang yang sama dengan menambah faktor intervensi didalamnya.

\section{DAFTAR PUSTAKA}

Dewi, I., \& Suryana, D. (2020). Analisis Evaluasi Kinerja Pendidik Pendidikan Anak Usia Dini di PAUD Al Azhar Bukittinggi. Jurnal Obsesi : Jurnal Pendidikan Anak Usia Dini, 4(2), 1051. https://doi.org/10.31004/obsesi.v4i2.465

Herlinda, S. (2017). Peran Komite Sekolah terhadap Kinerja Guru di TK Aisyiyah II Kota Pekan Baru. PAUD Lecture : Jurnal Pendidikan Anak Usia Dini, 1(1), 1-11. https://doi.org/https://doi.org/10.31849/paudlectura.v1i1.498

Ilmiah, W. S., Azizah, F. M., \& Amelia, N. S. (2019). Hubungan Pola Asuh Orang Tua dengan Perkembangan Anak Pra Sekolah di TK Mentari Desa Samba Rampak Lor Kecamatan Kota Anyar Kabupaten Probolinggo. JI-KES (Jurnal Ilmu Kesehatan), 2(2), 61-67. https://doi.org/10.33006/ji-kes.v2i2.116

Ilvagustina, I. (2016). Peningkatan Guru yang Sudah Tersertifikasi di Kecamatan Lebong Utara. Jurnal Ilmiah Potensia, 1(1), 50-55. https://ejournal.unib.ac.id/index.php/potensia/article/view/5661

Imelda, I. (2017). Pengetahuan Ibu tentang Pemberian Stimulasi dan Perkembangan Anak Pra Sekolah (3-5 Tahun) di Banda Aceh. Idea Nursing Journal, 8(3), 1-9. http://jurnal.unsyiah.ac.id/INJ/article/view/9487/7946

Intarti, W. D. (2019). Pengaruh KIE terhadap Tingkat Pengetahuan Guru PAUD tentang Stimulasi Kecerdasan Otak Anak Usia Dini. Jurnal Kebidanan Harapan Ibu Pekalongan, 6(2), 202-212. https://doi.org/10.37402/jurbidhip.vol6.iss2.56

Kristiawati, K., \& Yunitasari, E. (2018). Pemberdayaan PAUD Sebagai Upaya Peningkatan Pertumbuhan dan Perkembangan Anak Usia Dini. Buletin Udayana Mengabdi, 17(3), 47-51. https://doi.org/10.24843/bum.2018.v17.i03.p09

Maghfuroh, L., \& Chayaning, P. K. (2018). Pengaruh Finger Painting terhadap Perkembangan Motorik Halus Anak Usia Prasekolah di TK Sartika I Sumeurgenuk Kecamatan Babat Lamongan. Journal of Health Sciences, 10(1), 36-43. https://doi.org/10.33086/jhs.v10i1.144

Novianti, L. E., Noer, A. H., Qodariah, L., Moeliono, M. F., Pebriani, L. V., Joefiani, P., \& Ardiwinata, M. (2018). Program Psikoedukasi untuk Meningkatkan Pengetahuan Guru Pendidikan Anak Usia Dini (PAUD) di Kecamatan Jatinagor Kabupaten Sumedang tentang Ciri Perkembangan Anak Usia Prasekolah (2-5 
Tahun). Journal of Psychological Science and Profession, 2(1), 51-54. https://doi.org/10.24198/jpsp.v2i1.15286

Nurhidayah, I., Gunani, R. G., Ramdhanie, G. G., \& Hidayati, N. (2020). Deteksi dan Stimulasi Perkembangan Sosial pada Anak Prasekolah: Literatur Review. Jurnal Ilmu Keperawatan Anak, 3(2), 42-58. https://doi.org/http://dx.doi.org/10.26594/jika.1.2.2020. 42-58

Padila, P., Andari, F., \& Andri, J. (2019). Hasil Skrining Perkembangan Anak Usia Toddler antara DDST dengan SDIDTK. Jurnal Keperawatan Silampari, 3(1), 244-256. https://doi.org/https://doi.org/10.31539/jks.v3i1.809

Panzilion, P., Padila, P., Tria, G., Amin, M., \& Andri, J. (2020). Perkembangan Motorik Prasekolah antara Intervensi Brain Gym dengan Puzzle. Jurnal Keperawatan Silampari, 3(2), 510-519. https://doi.org/https://doi.org/10.31539/jks.v3i2.1120

Panzilion, P., Padila, P., Setyawati, A., J, H., \& Sartika, A. (2020). Stimulation of Preschool Motor Development Through Brain Gym and Puzzle. JOSING: Journal of Nursing and Health, 1(1), 10-17. https://doi.org/10.31539/josing.v1i1.1166

Primihastuti, D. (2020). Tingkat Pengetahuan Orang Tua tentang Stimulasi Perkembangan Anak Pra Sekolah Usia 3-5 Tahun. Midwifery Journal of Akbid Griya Husada Surabaya, 7(1), 61-66. http://griyahusada.id/journal/index.php/midwifery/article/view/99

Qomario, Q., Kurniasih, S., \& Anggraini, H. (2018). Studi Analisis Latar Belakang Pendidikan, Sertifikasi Guru dan Usia Guru PAUD di Kota Bandar Lampung Berdasarkan Hasil Nilai Uji Kompetensi Guru (Ukg). Jurnal Caksana: Pendidikan Anak Usia Dini, 1(2), 1-10. https://doi.org/10.31326/jcpaud.v1i02.180

Rahayu, C. D., \& Purnamasari, I. (2019). Pelatihan SDIDTK untuk Meningkatkan Pengetahuan Guru PAUD dalam Melakukan SDIDTK di Kabupaten Wonosobo. Jurnal Penelitian dan Pengabdian Kepada Masyarakat UNSIQ, 6(1), 31-36. https://doi.org/10.32699/ppkm.v6i1.498

Ramadhani, H. P., Ratnawati, M., \& Alie, Y. (2018). Hubungan Status Gizi dengan Perkembangan Anak Usia 3-5 Tahun di Pendidikan Anak Usia Dini (PAUD) Midanutta'lim Desa Mayangan Kecamatan Jogoroto Kabupaten Jombang. Journal of Health Sciences, 10(1), 53-59. https://doi.org/10.33086/jhs.v10i1.145

Riyadi, E. K. S., \& Sundari, S. (2020). Tingkat Pengetahuan Orang Tua tentang Stimulasi Perkembangan Anak Pra Sekolah Usia 60-72 Bulan. Jurnal Ilmu Kebidanan, 6(2), 59-67. http://jurnal.akbiduk.ac.id/assets/doc/210106120403

Saputri, S. N. (2019). Hubungan Frekuensi Stimulasi dengan Perkembangan Anak Usia 60-72 Bulan Di TK Syech Abu Bakar Surabaya [Universitas Airlangga]. http://repository.unair.ac.id/84888/

Setyaningsih, R., \& Anggasari, N. (2017). Hubungan Tingkat Pengetahuan Orang Tua tentang Stimulasi Verbal dengan Pekembangan Bahasa pada Anak Usia Dini di TK Yayasan Bhakti Siwi Desa Soran Kabupaten Klaten. KOSALA : Jurnal Ilmu Kesehatan, 5(2), 83-90. https://doi.org/10.37831/jik.v5i2.129

Siswina, T., Shahib, N., \& Rasyad, A. S. (2016). Pengaruh Stimulasi Pendidikan terhadap Perkembangan Kecerdasan Anak Usia 3-6 Tahun. Jurnal Ilmiah Bidan, 1(2), 27-33. https://e-journal.ibi.or.id/index.php/jib/article/view/7/5

Suryandari, A. E., \& Purwanti, S. (2018). Analisi Pengetahuan Guru PAUD/TK tentang SDIDTK dengan Pelaksanaan Deketsi Penyimpangan Perkembangan Balita. 
Jurnal Publikasi Kebidanan, 9(1), 1-10. http://www.akbidylpp.ac.id/ojs/index.php/Praa/article/view/394/48484850

Ulfa, M. (2018). Analisa Deteksi Dini dan Stimulasi Perkembangan Anak Usia Prasekolah. Care: Jurnal Ilmiah Ilmu Kesehatan, 6(3), 200-209. https://doi.org/10.33366/cr.v6i3.1002

Winarsih, B. D., \& Hartini, S. (2020). Peningkatan Pengetahuan Guru PAUD tentang Deteksi Tumbuh Kembang Anak Menggunakan KPSP. Jurnal Pengabdian Kesehatan, 3(2), 100-108. https://doi.org/10.31596/jpk.v3i2.82

Yuliani, I. (2018). Pelatihan Stimulasi Deteksi Intervensi Dini Tumbuh Kembang (SDIDTK) Bagi Guru dan Wali Murid PAUD pada PAUD Baitunnur Gentan Sinduharjo Ngaglik Sleman. Jurnal Pengabdian Dharma Bakti, 1(1), 30-38. http://dharmabakti.respati.ac.id/index.php/dharmabakti/article/view/14 